\title{
Parameter Identification System of the Oceanic Heat Flux between Ice and Ocean
}

\author{
Yu Yang \\ Department of Basic Sciences, Shenyang Institute of Engineering \\ Shenyang, China \\ yangyang-0606@hotmail.com
}

\begin{abstract}
According to the energy balance equation at the ice bottom, the ice bottom energy balance system has been given, and the existence and uniqueness of the solution of the system has been proved. The oceanic heat flux is selected as identified parameter and the the ice thickness deviation as the performance criterion, so that the optimal identification model has been presented. The existence of the optimal solution and the optimality conditions of the optimal identification model have been considered by using the theory of bounded variation. This method to estimate the oceanic heat flux is only controlled by observed ice thickness, which can overcome the calculated bias caused by the technique error of observed temperature and the empirical parameters in other methods. Based on the the field campaigns of landfast sea-ice thermodynamic observation off Zhongshan Station in Prydz Bay, East Antarctica in March 2006 to November 2006, the time series of the oceanic heat flux and the oceanic heat flux fitting function of time has been derived.
\end{abstract}

Keywords-parameter identification; optimal control; ice and snow; thermodynamics

\section{INTRODUCTION}

Thermodynamic evolution of sea thickness is forced by heat fluxes at its upper and lower boundaries and penetration of solar radiation into the ice sheet. Much research work has been done on the heat fluxes at the upper surface by measurement campaigns and analytical and numerical modelling. The lower boundary, i.e. oceanic heat flux from the liquid water body into the bottom of the ice sheet is less understood ${ }^{[1]}$. The oceanic heat flux exerts a large influence on the formation and the thickness of sea ice. Global sea ice climate models have proved to be highly sensitive to the oceanic heat flux.

Oceanic heat flux can be determined from vertical profiles of ocean temperature, salinity and current speed and ice bottom roughness. In previous studies, in the Arctic an oceanic heat flux of $2 \mathrm{~W} / \mathrm{m}^{2}$ is widely considered to be a reasonable annual average value ${ }^{[2-3]}$, but much higher values are generally used in Antarctic seas. Reference [4] set oceanic heat flux as a constant $25 \mathrm{~W} / \mathrm{m}^{2}$ in their large-scale model throughout the year. Gordon and Huber derived a mean oceanic heat flux of $16 \mathrm{~W} / \mathrm{m}^{2}$ for the section of the Greenwich meridian between $60^{\circ}$ and $70^{\circ} \mathrm{S}$ in the Weddell Sea ${ }^{[5]}$. According to the observations of sea ice mass balance and temperature made during the yearlong Surface Heat budget of the Arctic Ocean (SHEBA) field experiment, Perovich and Elder estimated monthly oceanic heat fluxes for a variety of ice types: $7.5 \mathrm{~W} / \mathrm{m}^{2}$ for undeformed ice, $10.4 \mathrm{~W} / \mathrm{m}^{2}$ for a melt pond and $12.4 \mathrm{~W} / \mathrm{m}^{2}$ for an old ridge ${ }^{[6]}$. Allison examined fast ice cover at the Antarctic station Mawson and found two peaks in the oceanic heat flux during the ice growth season ${ }^{[7]}$. One peak occurred during initial ice growth, caused by the ice growth itself, since a rapid ice growth sets up thermohaline convection, which deepens the mixed layer by pumping warmer water upward. Another, minor peak at the time of maximum ice thickness, was attributed to larger-scale oceanic processes $^{[8]}$.

In this study, the oceanic heat flux is first to select as identified parameter and the ice thickness deviation as the performance criterion, so that the optimal identification model has been presented. The existence of the optimal solution and the optimality conditions of the optimal identification model have been considered by using the theory of bounded variation. This method to estimate the oceanic heat flux is only controlled by observed ice thickness, which can overcome the calculated bias caused by the technique error of observed temperature and the empirical parameters in other methods.

\section{PARAMETER IDENTIFICATION SYSTEM}

\section{A. Energy balance system at ice bottom}

The coupled sea ice system we consider consists of two layers: the sea ice layer and the ocean mixed layer, denoted by ice-ocean system (Fig .1).

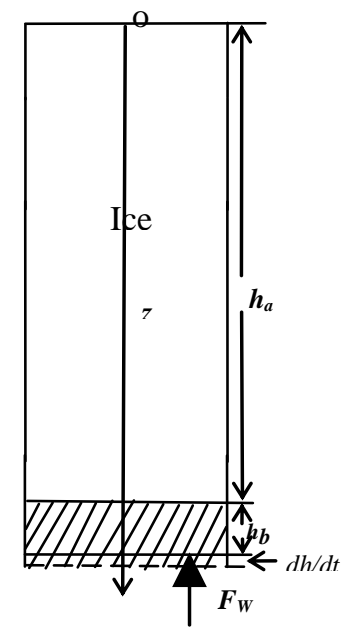

Figure.1 Principle of energy balance at ice bottom layer 
In this system, since the gradient change in the vertical direction is far greater than the one in the horizontal direction, we only consider the oceanic heat flux in the vertical direction. In Fig.1, the vertical coordinate $\mathrm{z}$ representing the depth of the ice-ocean system is taken as positive downward. ha, hb and hbmax denote the depth from the ice surface to bottom thin layer, the ice bottom depth and its maximum, respectively. $t \in I=[0, t f]$ is time, tf is the final time $(0<\mathrm{tf}<\infty)$. Tf denote the temperature at ice bottom, $\mathrm{q}(\mathrm{ha}, \mathrm{t})$ is the penetrating solar radiation, Let $\Omega a=(0$, ha), $\Omega b=($ ha, hb+hbmax $), \Omega=\Omega a \cup \Omega b=(0, h)$, $\mathrm{Qi}=\Omega \mathrm{i} \times \mathrm{I}, \mathrm{i} \in \mathrm{L}=\{\mathrm{a}, \mathrm{b}\}$. The energy balance between the ice and ocean is described by the following equation:

$$
\begin{aligned}
-\rho_{i} L_{f} \frac{\partial\left(h_{a}+h_{b}\right)(z, t)}{\partial t}= & -k_{i} \frac{\partial T\left(\left(h_{a}+h_{b}\right)(z, t), t\right)}{\partial z} \\
& -\frac{\partial q\left(\left(h_{a}+h_{b}\right)(z, t), t\right)}{\partial z}+F_{w}(z, t),(z, t) \in Q_{b}
\end{aligned}
$$

where $\rho_{i}, L_{f}$, and $k_{i}$ are the ice density, fusion heat and thermal conductivity, respectively. $F_{w}(z, t)$ is oceanic heat flux.

If sea ice is thicker than $50 \mathrm{~cm}$, we can set $q\left(h_{a}, t\right)$ equal to $0 \mathrm{~W} / \mathrm{m}^{2}$. So the energy balance can be simply to $-\rho_{i} L_{f} \frac{\partial\left(h_{a}+h_{b}\right)(z, t)}{\partial t}=-k_{i} \frac{\partial T\left(\left(h_{a}+h_{b}\right)(z, t), t\right)}{\partial z}+F_{w}(z, t),(z, t) \in Q_{b}$

$\rho_{i}, L_{f}$ are non-zero, then

$\frac{\partial\left(h_{a}+h_{b}\right)(z, t)}{\partial t}=\frac{k_{i}}{\rho_{i} L_{f}} \cdot \frac{\partial T\left(\left(h_{a}+h_{b}\right)(z, t), t\right)}{\partial z}-\frac{F_{w}(z, t)}{\rho_{i} L_{f}}, \quad(z, t) \in Q$

In this paper, we only consider the ice bottom layer, ha and $T(t)$ can be simulated by optimization algorithm ${ }^{[9]}$, so ha is constant in (3). And the ice bottom layer is small portion of total ice thickness, we can neglect the vertical change of $\left(h_{b}(z, t)\right)$ and $(F w(z, t))$, then

$h\left(t, h_{b}(t), F_{w}(t)\right)=\frac{k_{i}}{\rho_{i} L_{f}} \cdot \frac{T\left(h_{a}+h_{b}(t)\right)-T\left(h_{a}\right)}{h_{b}(t)}-\frac{F_{w}(t)}{\rho_{i} L_{f}}, \quad t \in I$

Thus the ice bottom layer energy balance can be described by the following parabolic partial differential equation:

$$
\begin{gathered}
\mathrm{IOE}: \quad \frac{d h_{b}(t)}{d t}=h\left(t, h_{b}(t), F_{w}(t)\right), \quad t \in I \\
h_{b}(0)=h_{0}
\end{gathered}
$$

According to the physical properties of sea ice, we can give the following assumptions:

(A1) $\rho_{i}, L_{f}$ and $k_{i}$ are positive constants.

(A2) The depth of ice bottom layer $h_{b}(t)$, oceanic heat flux $F_{w}(t)$ and its derivative $F_{w}^{\prime}(t)$ are bounded continuous on

$I$, that $\quad h_{b 1} \leq h_{b}(t) \leq h_{b 2} \quad, \quad f_{w 1} \leq F_{w}(t) \leq f_{w 2} \quad$, $f_{w 11} \leq F_{w}^{\prime}(t) \leq f_{w 12}$.

From assumption (A2), define

$$
F=\left\{F_{w}(t) \in \mathrm{C}(I, R) \mid f_{w 1} \leq F_{w}(t) \leq f_{w 2}, t \in I\right\}
$$

$F$ is the permissible control set of $F_{w}(t)$, and $F$ is the compact convex set in $R$.

\section{Parameter Identification System}

In this section we consider the identification problem of system (IOE). Suppose that there are $m$ observations in $I$, $t_{j} \in I, j \in I_{m}=\{1,2, \ldots, m\}$ denote the observed time, $\left\{h_{o b s}\left(t_{j}\right) \mid j \in I_{m}\right\}$ is the set of ice observations, $h_{o b s}(t) \in \mathrm{C}^{1}(Q, R) \quad$ denote the simulated ice thickness. $\forall F_{w}(t) \in F$, the performance criterion is given by

$$
\begin{aligned}
J\left(F_{w}(t)\right) & =J\left(h_{b}\left(t \mid F_{w}(t)\right)\right) \\
& =\int_{I}\left[h_{b}\left(t \mid F_{w}(t)\right)+h_{a}(t)-h_{o b s}(t)\right]^{2} d t
\end{aligned}
$$

Our goal is to make the ice thickness $h_{b}\left(t \mid F_{w}(t)\right)$ approach the observations, then the identification model of system (IOE) denoted by (SIFW) can be expressed as

$$
\begin{array}{ccc}
\text { SIFW : } & \min & J\left(F_{w}(t)\right) \\
& \text { s.t. } & h_{b}\left(t \mid F_{w}(t)\right) \in S(F), \quad\left(z_{b}, t\right) \in Q_{b} \\
& F_{w}(t) \in F
\end{array}
$$

where $S(F)=\left\{h_{b}\left(t \mid F_{w}(t)\right) \in L^{2}\left(0, t_{f} ; F\right) \mid h_{b}\left(t \mid F_{w}(t)\right)\right.$ is the solution of system (IOE) corresponding to $\left.F_{w}(t) \in F(\mathrm{IOE})\right\}$

We will prove the existence and uniqueness of the system (SIFW) solution.

Lemma 1. Suppose (A2) hold, then

(a) $\forall F_{w}(t) \in F$, 则 $F_{w}(t) \in B V\left(I,\left[f_{w 1}, f_{w 2}\right]\right)$;

(b) For given $\left\{F_{w}^{n}(t)\right\} \subseteq F, \exists \bar{C}>0$, so that

$$
\begin{aligned}
\left|F_{w}^{n}(t)\right| \leq \bar{C}, \forall t \in I, n=1,2, \mathrm{~L}, \\
\bigvee_{0}^{{ }_{f}} F_{w}^{n}(t) \leq \bar{C}, \forall n
\end{aligned}
$$

Proof. (a). According to (A2), $F_{w}(t)$ is continuous and differentiable, and for any partition $p=\left\{\tau_{0}, \tau_{1}, \mathrm{~L}, \tau_{n_{p}}\right\}$ in I,

$$
\begin{array}{r}
\sum_{i=1}^{n_{p}}\left|F_{w}\left(\tau_{i}\right)-F_{w}\left(\tau_{i-1}\right)\right| \leq \sum_{j=9}^{N-1} \sum_{\substack{\left.\tau_{k-1}, \tau_{k}\right) \\
\subset\left(t_{2 j+1}, t_{j+2}\right)}}\left|F_{w}^{\prime}\left(\theta_{k}\right)\right|\left|\tau_{k-1}-\tau_{k}\right|+(2 N-1) f_{w 2} t_{f}, \\
\forall F_{w}(t) \in F
\end{array}
$$

where $\theta_{k} \in\left(\tau_{k-1}, \tau_{k}\right)$.

$$
\sum_{i=1}^{n_{p}}\left|F_{w}\left(\tau_{i}\right)-F_{w}\left(\tau_{i-1}\right)\right| \leq L t_{f}+(2 N-1) f_{w 2} t_{f}, \quad \forall F_{w}(t) \in F
$$

where $L=\max _{t \in I}\left|F_{w}^{\prime}(t)\right|$. 


$$
\bigvee_{0}^{t_{f}} F_{w}(t) \leq+\infty, \forall F_{w} \in F
$$

(b) $\forall\left\{F_{w}^{n}(t)\right\} \subseteq F$, then

$$
\left|F_{w}^{n}(t)\right| \leq f_{w 2}, \forall t \in I, \text { and } n=1,2, \mathrm{~L},
$$

Let $\quad \bar{C}:=\max \left\{f_{w 2}, L t_{f}+(2 N-1) f_{w 2} t_{f}\right\}$ 。

Using the selection of total variation is irrelevant with $F_{w}(t),(5)$ can be solved.

Then we consider the problem of existence of optimal parameter.

Theorem 1. Based on (A1)-(A2), then there exists a unique solution $F_{w}(t)$ satisfying the system (IOE).

Proof. $\forall\left\{F_{w}^{n}(t)\right\} \subset F,\left\{F_{w}^{n}(t)\right\}$ is uniform bound. The subsequence $\left\{F_{w}^{n_{k}}(t)\right\}$ of $\left\{F_{w}^{n}(t)\right\}$ is the pointwise convergence to $F_{w}^{*}$ on $I$. We can get $F_{w}^{*} \in F$. There exists $h_{b}\left(t \mid F_{w}^{n_{k}}(t)\right)$ and $h_{b}\left(t \mid F_{w}^{*}(t)\right)$ are the solution of system (IOE) corresponding to $F_{w}^{n_{k}}(t)$ and $F_{w}^{*}(t)$, and continuous to $F_{w}(t)$.

And we can conclude that

$$
\lim _{k \rightarrow \infty} h_{b}\left(t \mid F_{w}^{n_{k}}(t)\right)=h_{b}\left(t \mid F_{w}^{*}(t)\right)
$$

$\forall t \in I$, then $h_{b}\left(t \mid F_{w}^{*}(t)\right) \in S(F)$. So $F$ is compact set.

$J\left(F_{w}(t)\right)$ is continuous according to $F_{w}(t)$, which implies the existence and uniqueness of the system (SIFW) solution $F_{w}^{*}(t)$. This completes our proof.

\section{OPTIMIZATION ALGORITHM}

\section{A. Optimization algorithm}

In this section, we will construct a feasible algorithm to solve the problem(SIFW). Let $j \in I_{m}=\{1,2, \ldots, m\}$ denote the observed spatial temporal number, thus (SIFW) can be rewritten as

$$
\begin{array}{cc}
\text { SIFWR : } \min \quad J\left(F_{w}(t)\right)=\sum_{t=1}^{m}\left[h_{b}\left(t_{j} \mid F_{w}\left(t_{j}\right)\right)+h_{a}\left(t_{j}\right)-h_{o b s}\left(t_{j}\right)\right]^{2} \\
\text { s.t. } \quad h_{b}\left(t \mid F_{w}\left(t_{j}\right)\right) \in S(F), \quad\left(z_{b}, t_{j}\right) \in Q_{b} \\
F_{w}\left(t_{j}\right) \in F
\end{array}
$$

Next we will construct an optimization algorithm to find the optimal solution.

Step 1. Input the observed ice thickness $\left\{h_{o b s}\left(t_{j}\right) \mid j \in I_{m}\right\}$.

Step 2. Generate $\mathrm{M}$ initial points $F_{w i}(i=1,2, \mathrm{~L} M) \in F$ at random, and $F(0)=\left\{F_{w i}(i=1,2, \mathrm{~L} M)\right\} \subset F \subset R$ is the initial population. Set $k=0$.

Step 3. Solve the system (SIFWR) to get fitness $F(k)$ for every observed time points.

Step 4. Select operator based on the proportion. To do the Arithmetic crossover and variation on the simulated unit, according to the crossover probability $\left(F_{c}\right)$ and mutation probability $\left(F_{m}\right)$.

Step 5. If $k \leq M$, set $k=k+1$, go to S3; else take $F_{w}^{*}=F_{w}(k)$, whose corresponding fitness is best, output the global optimal solution $F_{w}^{*}$.

\section{B. Numerical Results}

We take the observed ice thickness at Prydz Bay around Zhongshan Station $\left(69.37^{\circ} \mathrm{S}, 76.37^{\circ} \mathrm{E}\right.$, Fig .2) from March 2006 to December 2006 under a Chinese National Antarctic Research Expedition (CHINARE) program, which is a part of an International Polar Year (IPY). The shore-based snow and ice-monitoring programme commenced in March when the ice was safe to work. Measurements were conducted from the beach nearest to each survey section. The data included digital photography and written notes on the changes of surface conditions.

Beginning on 21 March, sea-ice thickness was measured through drill-holes every five days along a line at each measurement site. The accuracy of the drill-hole ice thickness was $\pm 5 \mathrm{~mm}$. Based on our available time series of measured ice thickness and snow thickness, the time period of our modelling experiments is from early April 2006 to end of November 2006.

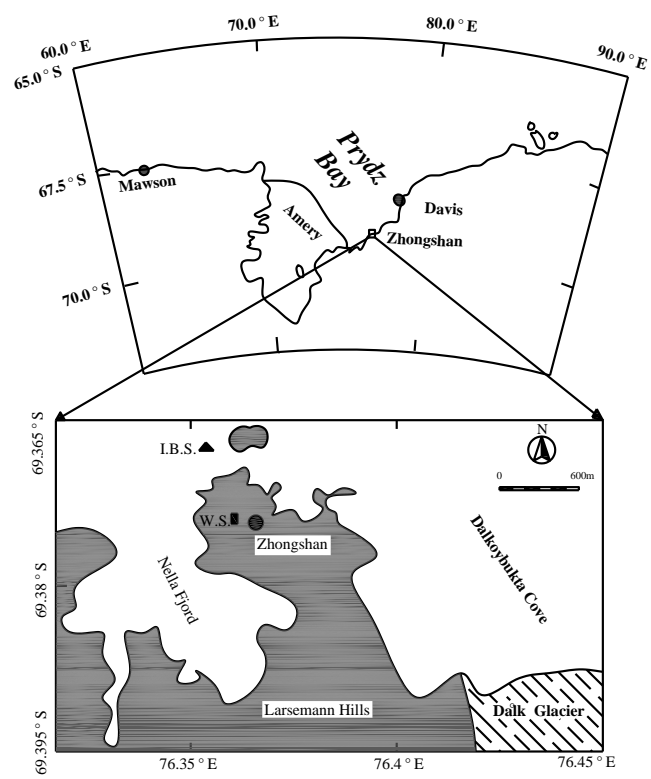

Figure 2. A map of Prydz Bay (top panel), and weather station (W.S.) and sea ice mass station (I.M.S) in low panel in/off Zhongshan Station.

The simulated result shows that estimated oceanic heat flux underneath the landfast sea ice in Prydz Bay decreases during ice growth and early melting period from about 25 $\mathrm{W} / \mathrm{m}^{2}$ on day 100 to $5 \mathrm{~W} / \mathrm{m}^{2}$ toward the end of the year (Fig.3).

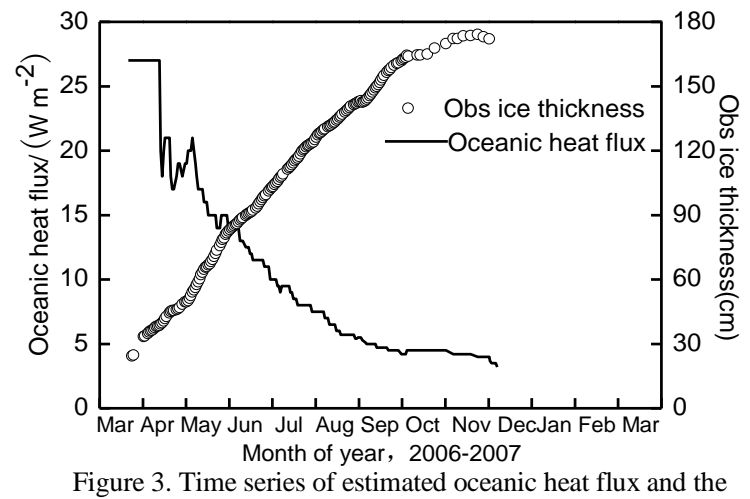
measured landfast sea ice thickness in Prydz Bay. In January-February 2007, the ice thickness and oceanic heat flux must return to the initial levels of the simulation. 
For consistency, between day 330 and day 450 (day 90 in the following year) the oceanic heat flux must go back to $20-30 \mathrm{~W} / \mathrm{m}^{2}$. It is likely that absorption of solar radiation in the Prydz Bay can provide this heat. As the ice thickness decreases, more radiation penetrates through also increasing the heat flux to the ice from the water. According to ice observations at the site, landfast ice is broken off by strong winds and drifted out. Thus the ice break-up and consequent absence of multi-year ice is due to mechanics.

\section{CONCLUSIONS}

In this paper, we are first to consider an optimal control problem for ice-sea thermodynamic system which can simulate oceanic heat flux. Based on the numerical results, we compared, for the ice growth season the computed oceanic heat flux and oceanic heat flux derived from in situ measurements by the heat flux residual method $^{[10]}$ (Fig .4).

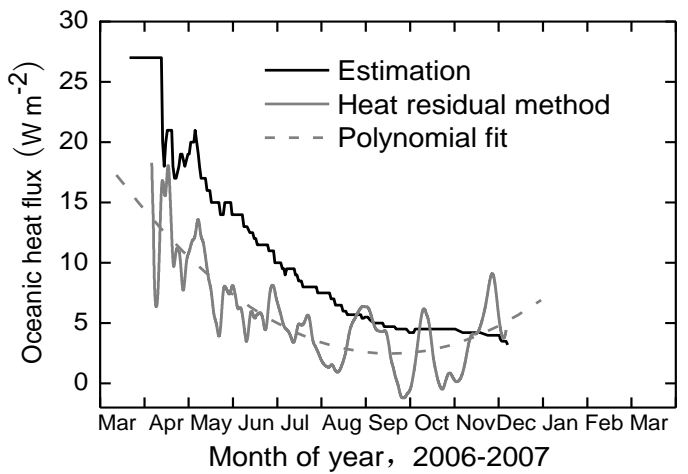

Figure 4. Time series of estimated oceanic heat flux by optimization algorithm and heat residual method. The grey dashed line is the polynomial fit to the result of the heat residual method.

The mean oceanic heat fluxes were $10.5 \mathrm{~W} / \mathrm{m}^{2}$ and 5.3 $\mathrm{W} / \mathrm{m}^{2}$ for optimization algorithm and the residual method, respectively. The heat residual method also produced a periodic 1-2 month oscillations, for which there is no clear explanation from the local ice-ocean physics point of view. The monotonically decreasing oceanic heat flux resulting from the optimization algorithm is more consistent with local ice/ocean physics.

\section{ACKNOWLEDGMENT}

This research received partly financial supported from National Natural Science Foundation of China (NSFC) under Contracts 11401392; Liaoning Educational Committee Foundation under Contracts L2013497.

\section{REFERENCES}

[1] M. Leppäranta, and K. Shirasawa. "Influence of oceanic heat flux on the ice thickness in Saroma-ko lagoon". Proceedings of the 22nd International Symposium on Okhotsk Sea \& Sea Ice, pp. 7 10, 2007.

[2] A. Semtner. 1976. "A model for the thermodynamic growth of sea ice in numerical investigations of climate". J. Phys. Oceanogr., vol. 6, pp. 379-389, 1976.

[3] R. Lei, N. Li, P. Heil, B. Cheng, Z. Zhang, B. Sun. "Multiyear sea ice thermal regimes and oceanic heat flux derived from an ice mass balance buoy in the Arctic Ocean". Journal of Geophysical Research, vol. 119, pp. 537-547, 2014, doi:10.1029/2008JC005223.

[4] C. Parkinson, and W. Washington. "A large-scale numerical model of sea ice". J. Geophys. Res., vol. 84, pp. 311-337, 1979.

[5] A. Gordon, and B. A. Huber. "Southern ocean winter mixed layer". J. Geophys. Res., vol. 95, pp. 11,655-11,672, 1990.

[6] D. Perovich. "The optical properties of sea ice". Cold Regions Research and Engineering Laboratory (CRREL) Report, 96-1, Hanover, NH., pp. 1-23, 1996.

[7] I. Allison. "Antarctic sea ice growth and oceanic heat flux". IAHS Publ., vol. 131, pp. 161-170, 1981.

[8] J. Wettlaufer. "Heat flux at the ice-ocean interface". Journal of Geophysical Research, vol. 96, pp.7215 - 7236, 1991 doi:10.1029/90JC00081.

[9] Y. Bai. "Parameter identification of non-smooth distributed parameter systems and its application". Phd. Thesis, Dalian University of Technology, 2006.

[10] R. Lei, Z. Li, B. Cheng, Z. Zhang, P. Heil. "Annual cycle of landfast sea ice in Prydz Bay, east Antarctica". Journal of Geophysical Research, vol. 115, 2010, doi:10.1029/2008JC005223. 